\section{Dengue in Southeast Asia: epidemiological characteristics and strategic challenges in disease prevention}

\author{
Dengue no Sudeste Asiático: características \\ epidemiológicas e desafios estratégicos na \\ prevenção da doença
}

Eng-Eong Ooi 1,2

Duane J. Gubler 2,3

\author{
${ }^{1}$ DSO National Laboratories, \\ Singapore. \\ 2 Duke-NUS Graduate \\ Medical School Singapore, \\ Singapore. \\ 3 Asia-Pacific Institute \\ for Tropical Medicine \\ and Infectious Diseases, \\ University of Hawaii, \\ Honolulu, U.S.A. \\ Correspondence \\ E. -E. Ooi \\ DSO National Laboratories. \\ 27 Medical Drive, \#09-01k \\ Singapore 117510 \\ oengeong@dso.org.sg
}

\begin{abstract}
Dengue emerged as a public health burden in Southeast Asia during and following the Second World War and has become increasingly important, with progressively longer and more frequent cyclical epidemics of dengue fever/dengue hemorrhagic fever. Despite this trend, surveillance for this vector-borne viral disease remains largely passive in most Southeast Asian countries, without adequate laboratory support. We review here the factors that may have contributed to the changing epidemiology of dengue in Southeast Asia as well as challenges of disease prevention. We also discuss a regional approach to active dengue virus surveillance, focusing on urban areas where the viruses are maintained, which may be a solution to limited financial resources since most of the countries in the region have developing economies. A regional approach would also result in a greater likelihood of success in disease prevention since the large volume of human travel is a major factor contributing to the geographical spread of dengue viruses.
\end{abstract}

Dengue; Disease Prevention; Communicable Diseases

\section{Introduction}

Dengue fever/dengue hemorrhagic fever is a reemerging disease that is endemic throughout the tropical world, with frequent and cyclical epidemics. The disease is caused by the dengue viruses, a Flavivirus that is transmitted principally by the Aedes aegypti mosquito. Other mosquito species such as Ae. albopictus and Ae. polynesiensis can also transmit epidemic dengue, but do so less efficiently ${ }^{1,2}$. The virus has four antigenically similar but immunologically distinct serotypes. Thus a person can be infected with the dengue virus up to four different times. Furthermore, epidemiological observations suggest that a person's risk of developing dengue hemorrhagic fever, characterized by increased plasma leakage as a result of alteration in microvascular permeability 3 , increases with subsequent infections 4 . If not properly managed, the mortality of dengue hemorrhagic fever can be as high as $30 \% 5$. There is as yet no specific treatment for dengue fever or dengue hemorrhagic fever although with proper clinical diagnosis and management, dengue hemorrhagic fever mortality rates are $<1 \%$; efforts to develop anti-dengue drugs are in progress. Prevention of this disease is thus imperative. While vaccines for other flaviviruses such as yellow fever and Japanese encephalitis have been developed, dengue vaccine development is complicated by the need to incorporate all four virus serotypes into a single formulation. An approved 
vaccine is thus not likely to be available for five to ten years; the only way to prevent dengue transmission, therefore, is to reduce the population of its principal vector, Ae. aegypti.

\section{Dengue in Southeast Asia}

Dengue emerged as a public health burden in Southeast Asia following the Second World War, which led to significant ecological disruption and demographic changes. The movement of equipment and people during the war resulted in the transportation of Ae. aegypti to new geographic areas. The use of containers to store water for domestic use and fire control following destruction of the then existing water systems, along with the presence of discarded war equipment and junk, all served as ideal breeding habitats for Ae. aegypti. Together, these factors contributed to the expanded geographic distribution and population densities of Ae. aegypti. The movement of Japanese and Allied troops in and out of the region also served to provide susceptible hosts for dengue virus 6 .

Although the Second World War served to expand the geographic distribution of the dengue viruses and their vector, it was the urbanization of Southeast Asia after the war that provided the ideal conditions for virus propagation. Millions of people moved to the cities seeking work, resulting in hurried but unplanned growth of urban centers in many parts of Southeast Asia. Housing, water supply and sewerage systems were inadequate. This mixture of an ideal breeding habitat for the highly domesticated $A e$. aegypti as well as susceptible human hosts resulted in epidemic dengue.

It was thus in this setting that dengue emerged as a leading public health burden in Southeast Asia. Manila, Philippines recorded the first dengue hemorrhagic fever outbreak in $1953 / 1954$, with a second outbreak two years later in 1956 6. Bangkok had an epidemic in 1958 although sporadic cases of dengue hemorrhagic fever were identified in Thailand throughout the 1950 s 7,8 . The significance of dengue hemorrhagic fever as a public health burden may be appreciated from Halstead's Alexander D. Langmuir lecture in 1981: "Dengue hemorrhagic fever is an important cause of morbidity and mortality predominantly, but not exclusively, in children in tropical Asia. Over half a million persons have been hospitalized with this syndrome in the past 20 years, more than 200,000 in the past two years alone" 9 (p. 632-3).

The cyclical dengue epidemics in Southeast Asia that started in the 1950s have continued to the present time, with each epidemic being larger in magnitude than before. Figure 1 shows the incidence of dengue fever/dengue hemorrhagic fever in Southeast Asian countries in this millennium, from 2000 to 2005, with data obtained from WHO's DengueNet (http://www.who.int/ globalatlas). The data presented in this figure is likely to represent only a fraction of the total disease burden since some countries do not report dengue fever but only dengue hemorrhagic fever. Furthermore, since most countries rely on a passive surveillance system, infections resulting in less severe dengue disease or unusual clinical presentations 10,11 would likely have gone undiagnosed etiologically. Nonetheless, it is apparent that the trend in dengue activity will continue unabated well into the $21^{\text {st }}$ Century.

\section{Current developments in Southeast Asia}

The urbanization of Southeast Asia that started after World War II continues to this day. Figure 2 shows data obtained from the United Nations' World Urbanization Prospects: the 2005 Revision Population Database, where the increasing trends observed since the 1950s in both the urban population size as well as the proportion of the total population living in urban areas are likely to continue for the next few decades 12 . Not all of this population expansion is directly due to increases in birth rates. In Singapore, the population is growing at a rate of $4.4 \%$ in 2007 (htt:// www.singstat.gov.sg/stats/keyind.html). However, the total fertility rate per resident female is only 1.26 . These indicate that population expansion is through the immigration of foreigners, many of whom would likely be from the developed world and are attracted to the thriving economy of this city state. Moreover, urban population growth in many Southeast Asian countries is due to rural people migrating to the cities for economic purposes 12 . This trend would result in further increases to the population density of susceptible human hosts.

The impact of this population expansion and urbanization of Southeast Asia can be understood by studies carried out by Cummings et al. ${ }^{13}$. They have suggested, using mathematical modeling, that dengue virus resides in and spreads out of Bangkok and other urban centers, to the rest of the region, moving at a speed of 148 kilometers per month. This spread occurred in three-yearly waves of large outbreaks, each driven by a change in the predominant serotype of dengue virus. Similarly, surveillance data suggested that the 1976-1977 epidemics of dengue hemorrhagic fever caused by DEN-3 in 


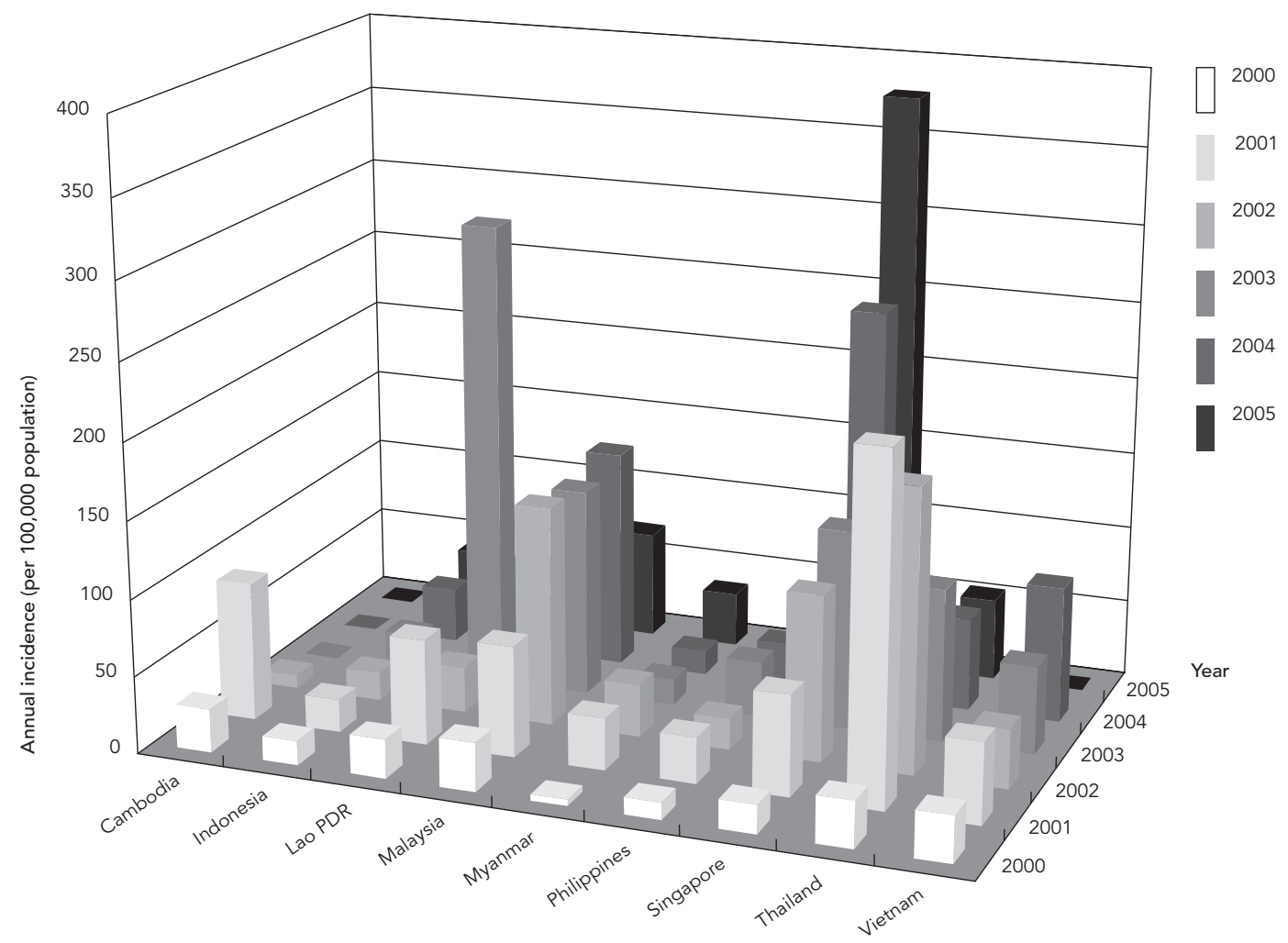

Source: data obtained from WHO's DengueNet (http://www.who.int/globalatlas).

Indonesia, began in Jakarta and spread out from that city 14,15 . With further expansion of the urban populations, dengue activity will remain at a level favorable for the continuation of cyclical epidemic activity, with each cycle being larger in magnitude 12,13,15.

Mass air transport serves as an efficient means for transporting dengue virus between urban centers of the tropics. This activity has increased in Southeast Asia through increased trade and travel across the region. In 2006, Singapore reported a total of 107,092 aircraft landings, with a combined total of over 35 million people passing through this airport alone, a figure that is nearly nine times the population of Singapore. The number of travelers passing through other major airports in Southeast Asia, such as those in Kuala Lumpur and Bangkok are also similar in numbers.
While the population and urban centers have increased in size in Southeast Asia, the public health infrastructure has not been able to keep up with this pace in many countries. Increasing numbers of people continue to live with inadequate access to good housing, clean water, sewage and waste management systems, thus increasing exposure to mosquito vectors that transmit dengue and other diseases 1,12 . Access to vector control and disease prevention programs is even more limited although those places that have implemented community-based programs along with the use of both old and new vector control tools have had positive effects on preventing disease transmission $16,17,18,19$. It is likely that this lack of development in the public health infrastructure will continue to allow Ae. aegypti to thrive, increasing its geographical distribution and population densities. 
Total population and percentage of population living in urban areas in Southeast Asia, including Timor Leste, from 1950 and projected to 2030 .

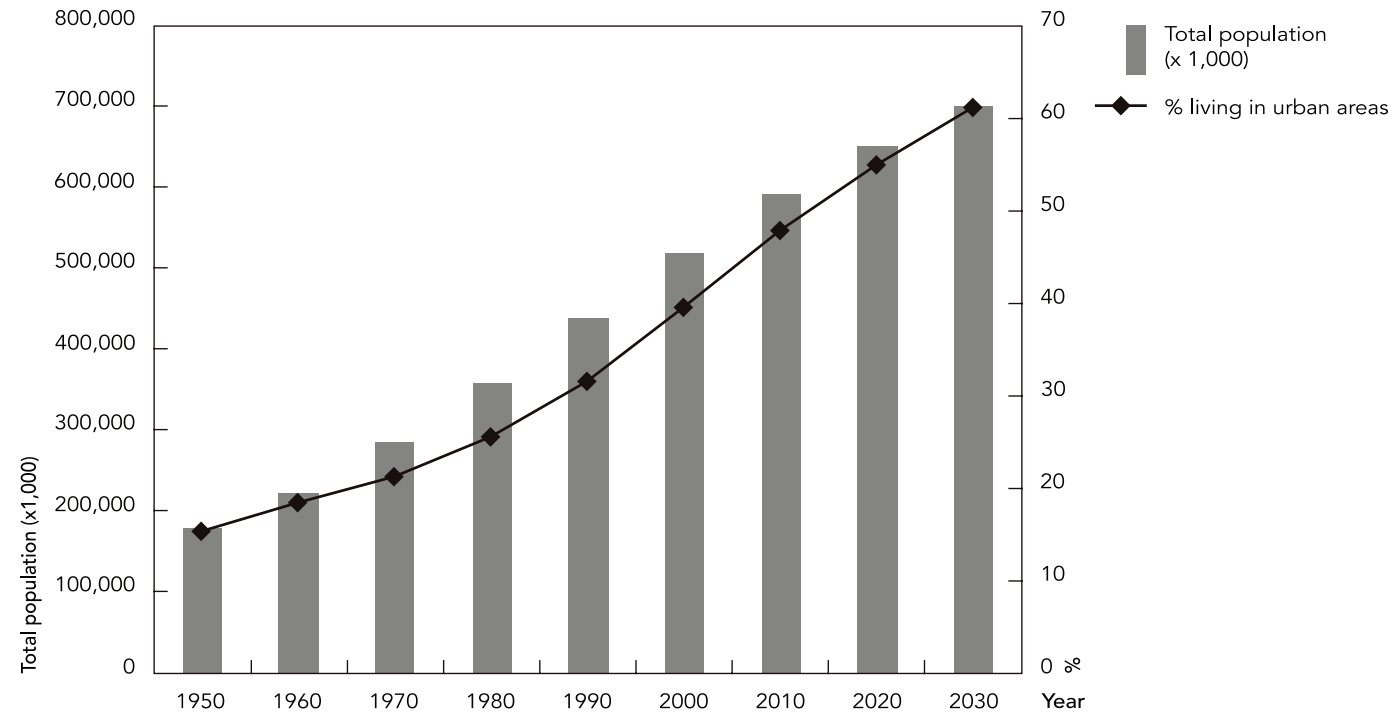

Source: data obtained from the United Nations' World Urbanization Prospects: The 2005 Revision Population Database.

\section{How should Southeast Asia respond to dengue?}

Dengue fever/dengue hemorrhagic fever surveillance is an important component of any disease prevention and control program 20 . The primary goal of public health surveillance is to monitor dengue transmission in a community to guide effective programs to prevent the occurrence and spread of the disease. Other goals for surveillance include defining disease severity, determining the cost-effectiveness of public health prevention programs, and estimating the burden of disease in the community. The ideal surveillance program should thus be able to monitor dengue cases accurately, predict impending epidemics from a background of endemic disease and trigger the necessary preventive measures.

While it is clear that surveillance is the cornerstone of dengue virus transmission prevention, the literature suggests that much could yet be done to improve the sensitivity and specificity of most surveillance programs 20,21,22,23,24. Most Southeast Asian countries acknowledge the need for disease surveillance and emergency response but few have the infrastructure and functional systems to support such a system. Dengue virus transmission continues to be monitored by passive surveillance of dengue cases. Table 1 is an extract from a recent review of research needs for dengue surveillance and emergency response 23 , which is an update of a review of surveillance systems in dengue-endemic countries by Gubler 24 . The table is a subjective evaluation of the status and efficiency of the surveillance systems, and whether these are supported by laboratory capabilities with early warning predictive capabilities for epidemic transmission. It also attempts to capture whether countries report both dengue fever and dengue hemorrhagic fever or dengue hemorrhagic fever alone, based on data obtained from WHO's DengueNet, a global real-time information exchange system for dengue-endemic countries to share surveillance data on a timely basis with each other and with the WHO. The findings in 200623 are largely similar to those reported in 2002 24. With a few exceptions, most Southeast Asian countries do not have the systems in place for active, laboratory-based surveillance, and therefore, for effective emergency response, or effective prevention programs. Instead, there is over reliance on passive surveillance systems without uniformity in case definitions used. Moreover, most countries do not even enforce laws that make dengue a notifiable disease. 
Southeast Asian countries and their dengue fever/dengue hemorrhagic fever surveillance capabilities.

\begin{tabular}{|c|c|c|c|c|c|c|}
\hline \multirow[t]{3}{*}{ Southeast Asian countr } & \multicolumn{3}{|c|}{ Surveillance } & \multicolumn{2}{|c|}{ Lab capability } & \multirow{3}{*}{$\begin{array}{l}\text { Epidemic } \\
\text { prediction }\end{array}$} \\
\hline & \multicolumn{2}{|c|}{ Passive } & \multirow{2}{*}{$\begin{array}{c}\text { Active } \\
\text { Dengue fever/ } \\
\text { dengue } \\
\text { hemorrhagic fever }\end{array}$} & \multirow[b]{2}{*}{ Serology } & \multirow[b]{2}{*}{ Virology } & \\
\hline & Dengue & $\begin{array}{c}\text { Dengue } \\
\text { hemorrhagic } \\
\text { fever }\end{array}$ & & & & \\
\hline Brunei & + & ++ & - & + & + & - \\
\hline Cambodia & + & ++ & - & ++ & $+*$ & - \\
\hline Indonesia & - & +++ & - & + & $+*$ & - \\
\hline Laos & + & + & - & - & - & - \\
\hline Malaysia & ++ & +++ & + & +++ & +++ & + \\
\hline Myanmar & - & ++ & - & + & + & - \\
\hline Philippines & + & + & - & ++ & + & - \\
\hline Singapore & +++ & +++ & + & +++ & +++ & + \\
\hline Thailand & - & +++ & - & ++ & $++*$ & - \\
\hline Vietnam & + & +++ & - & ++ & +++ & - \\
\hline
\end{tabular}

The efficacy of the surveillance system and laboratory capability is rated as follows:

(-) Surveillance or public health laboratory capability does not exist; (+) exists; (++) good; (+++) best.

* Does not include US Military, Centers for Disease Control and Prevention (CDC), Institute Pasteur or World Health Organization $(\mathrm{WHO})$ laboratories.

Over reliance on passive surveillance systems

Passive surveillance relies on healthcare professionals to notify public health authorities of all suspected or laboratory-confirmed dengue cases. However, passive surveillance systems are not suitable for monitoring dengue virus transmission. Such a surveillance system is uniformly insensitive because of low index of suspicion for dengue, particularly during the inter-epidemic periods 21,25. Furthermore, dengue infection results in a spectrum of clinical outcomes: from completely asymptomatic, undifferentiated viral syndrome, dengue fever, dengue hemorrhagic fever, to dengue shock syndrome, and other severe manifestations such as neurotropic disease and hepatic failure 26 . Passive surveillance using dengue fever/dengue hemorrhagic fever case definitions alone lack specificity since many other infectious diseases that are either endemic or cause periodic epidemics in Southeast Asia, such as influenza, chikungunya fever, enterovirus infections, leptospirosis, malaria and typhoid fever all present with similar symptoms and signs as dengue in the acute phase of illness 26,27.

Another important consideration is that the use of passive surveillance alone also ignores the patients who present with undifferentiated febrile illness or viral syndrome. This group of patients represents a large proportion of those with symptomatic dengue infection, depending on the age of the patient and the strain of infecting virus 28 . Since it is difficult to differentiate mild dengue from other causes of undifferentiated fever clinically, it would be impossible to carry out passive surveillance on such dengue cases. This may contribute to a significant gap in our surveillance effort and possibly limit our epidemic prediction capability. Mild viral syndrome is of particular importance in monitoring dengue transmission during interepidemic periods when classical dengue fever and dengue hemorrhagic fever incidence is low 1,20 . In countries where dengue circulates hyperendemically, emergence of genetic variants with greater epidemic potential may be partially responsible for the cyclical outbreaks $14,15,29$ since certain viral clades appear to be more associated with increased transmission and severe disease outcomes 30,31,32,33. Virologic surveillance for cases that present with mild viral syndrome may yield such pre-epidemic isolates for comparative analysis. Although more work will need to be done before such data can be used for epidemic prediction, the key to understanding dengue epidemiology lies in better virologic surveillance during the inter-epidemic periods $15,20,21$. 
Lack of uniformity in the case definitions used

The current surveillance for dengue in Southeast Asia also lacks uniformity in case definition. Different countries classify dengue fever/dengue hemorrhagic fever differently, and there is variation in the types of dengue cases that are included in surveillance reports among countries that adopt different criteria for classifying dengue cases 23,24. Furthermore, some countries report only dengue hemorrhagic fever while others include dengue fever in their surveillance 23,24 . Recently, however, the usefulness of the existing dengue classification scheme and case definitions for dengue hemorrhagic fever according to the WHO guidelines has come under scrutiny 34 although this issue first surfaced as far back as 1983 35. Experiences from various parts of the world suggest that the usefulness of the case definition is not universal 29,35,36,37. Perhaps more importantly, the WHO case definition underestimates the severe dengue cases among adults 38 . This is a problem that needs to be addressed since adult disease is not just confined to travelers from developed countries. In Southeast Asia, dengue primarily affects the adult population in Singapore 39,40 , while the average age of infection has been observed to be increasing in other places 41,42 . Notwithstanding the current debate over the WHO case definition, there is also no consistency in the way these definitions are applied across dengue-endemic countries. All of these different practices contribute to the underestimation of the true extent of dengue transmission and limit the ability to compare surveillance data among countries and regions.

\section{Implementing active dengue virus surveillance for Southeast Asia}

Given the pivotal role dengue surveillance plays in disease prevention, it is apparent that passive surveillance alone will not generate sufficient information needed for outbreak prediction and the recommendation for an active surveillance system has been advocated by WHO and others since the 1980s 14,20,21,25,43,44. Virological surveillance should be conducted on patients that present with non-specific viral syndrome, classical dengue fever, with hemorrhagic or neurological manifestation and on all patients with a fatal outcome following viral prodrome 1,20,21,25. This approach, using sentinel physicians, clinics, and hospitals, would result in a more comprehensive surveillance for dengue virus transmission in the population. Yet, in Southeast Asia where dengue fever/dengue hemorrhagic fever epidemics are reported every three to six years, only Malaysia and Singapore have adequate laboratory capacity (Table 1) 23 . Most other countries continue to rely on passive case notification for dengue hemorrhagic fever alone.

Possibly the fundamental reason why active surveillance is not widely implemented is likely to be the lack of financial resources. To establish an active, laboratory-based surveillance system, coupled with effective community-based, integrated vector control requires both the necessary public funds and political will. Unfortunately, most dengue-endemic countries have developing economies and resources. Such funds are often directed to other highly visible public programs instead of disease prevention. This problem, however, could be overcome by focusing the surveillance effort on where epidemics are likely to emerge. The work by Cummings et al. 13 has provided good data to support previous epidemiological observations that dengue epidemics emerge from urban environments and then spread to new areas 14,15. A focus on tropical urban areas could thus provide epidemic prediction and thus an early warning of dengue outbreaks despite limited resources.

While the implementation of active surveillance programs in urban centers of Southeast Asia would need to be carried out under the auspices of the local health authorities, the overall effort needs to be coordinated at the regional level. This need is perhaps emphatically highlighted by Singapore's near four decade experience with dengue surveillance and vector control 40. Dengue hemorrhagic fever appeared in Singapore in the 1960s and quickly became a major cause of childhood mortality. The public health response to dengue began in 1966 with a series of entomological and epidemiological surveys 45,46,47,48,49. Based on these studies, a surveillance-based vector control system was developed and implemented in 1968 50. Its main element was to reduce Aedes larval habitats, or larval source reduction, backed with public education and law enforcement. The implementation of this vector control program was completed in 1973, after which Singapore experienced a 15-year period of low dengue incidence until the 1990s, when epidemic dengue fever re-emerged with five- to seven-yearly cycles. Multiple factors contribute to this resurgence of dengue in Singapore and these have been reviewed previously 40 . One factor is likely to be the continued introduction of the virus from the Southeast Asian region through viremic travelers among the more than 35 million people that pass annually through Singapore's airport. Singapore's experience indicates that countries that attempt to prevent this viral dis- 
ease are doomed to failure due to re-importation of both virus and vector through a rising trend in regional and global travel. A coordinated regional approach to dengue prevention including active, laboratory-based surveillance is thus critical to success in Southeast Asia.

Several surveillance activities will benefit from such a regional coordination. One such effort is the establishment of a regional reference laboratory for dengue virus surveillance. Laboratory support is a critical component in surveillance $1,20,21$. In particular, the laboratory should be able to identify not only the presence of dengue virus, but also its serotype and correlate these to the severity of illness, and whether the patients are experiencing a primary or secondary dengue infection. Furthermore, information on the genetic sequence of the circulating viruses, both during and between dengue epidemics, would be of great value to our eventual ability to predict epidemics. Such a regional laboratory would complement and expand the WHO's DengueNet system, where morbidity and mortality data are shared among countries.

Such work requires funding for infrastructure support and human resource capability development. The countries that are more economically able to carry this load could and should take the lead in developing a surveillance network, especially since reducing virus transmission in the whole region is critical to reducing the incidence of dengue in the lead country itself.

Establishing a regional reference laboratory could also serve to standardize the laboratory methods used in surveillance, enabling the collection of data that can be compared among countries. Currently, many dengue-endemic countries lack laboratory support for dengue surveillance. Among those that do have laboratory support, there exists variation in laboratory methods used for virologic surveillance. This is especially true for molecular methods where the literature reports a large number of real-time or end-point RT-PCRs for dengue virus. These assays vary in their sensitivity and specificity. Importantly, many of the new serological assays have not been properly validated and tested for cross-reactivity to other viruses, especially co-circulating flaviviruses such as Japanese encephalitis, yellow fever and West Nile viruses. Standardization of the laboratory methods used for virologic and serologic surveillance, along with the establishment of an international quality assurance program for such laboratories, would yield clear benefits.

Apartfrom standardizing thelaboratorymethods used for surveillance, it would also be necessary for Southeast Asia to agree to harmonize the case definitions used for reporting dengue fever/ dengue hemorrhagic fever, which currently varies from country to country. Furthermore, there is often a lack of denominator data, or the extent to which the cases that fit the clinical entities are sampled for dengue virus. This limits the ability to make quantitative assessment of dengue transmission and thus compare the effectiveness of various preventive measures when these are applied in different places. As previously recommended 20,25, virologic surveillance should include patients that present with nonspecific viral syndrome, in addition to classical dengue fever, with hemorrhagic or neurologic manifestation and on all patients with a fatal outcome following viral prodrome. This approach would result in a more comprehensive surveillance of dengue virus transmission in the population.

Data obtained from active surveillance also needs to be translated into public health programs to prevent virus transmission. In the absence of a vaccine, control of the vector population density remains the only tool to achieve such a goal. Here, unlike virus surveillance, the approach to vector control would need to be tailored to suit the cities, towns and suburbs in each of the Southeast Asian countries. While the principle of reducing larval habitats may apply across the board, what works in one city or municipality may not be relevant to other places where the local ecology may be different. For example, Kay \& Nam ${ }^{16}$ and Nam et al. 17 reported remarkable success with vector and disease control with the use of copepods in water collecting barrels in Vietnam. Such an application would not be highly relevant in urban Singapore or Kuala Lumpur where the universal availability of potable water to all households makes water storage for domestic use unnecessary. Other examples abound 51,52 and thus vector control programs would need to be relevant to the local ecology.

The clear need in entomological surveillance, however, is an index or a measure of vector population density that may be predictive of epidemic dengue transmission 53 . It was thought from Singapore's experience in the 1970s that a premises index (the percentage of premises where Ae. aegypti larvae is found) of less than $5 \%$ was sufficient to prevent epidemic dengue 50 . However, since the 1990s, it is obvious that in Singapore, dengue incidence has increased dramatically, despite an overall premises index of two per cent and below 40 . This, however, may be due to the insensitive nature of a national premises index, where despite the low national index, there are places in Singapore where the Ae. aegypti population is high. Likewise, similar reports of limited ability to predict outbreaks have also been associated with the use of Bre- 
teau and container indices. A complicating factor is the role of herd immunity. Clearly, the vector population densities required for epidemic transmission are lower in regions with low herd immunity 54 .

\section{Other benefits of active surveillance and vector control}

Active surveillance and vector control also have the benefit of early identification and prevention of yellow fever in Southeast Asia. The potential for epidemic urban yellow fever is high with the increased movement of people via modern transportation 55 . Urban yellow fever could move very quickly from the American tropics to Southeast Asia, where an estimated 1.8 billion people are at risk. It can be difficult to distinguish yellow fever from severe dengue clinically and antibodies developed against yellow fever cross react with the commonly used serology for dengue diagnosis. Active virologic surveillance, however, would rapidly detect the introduction of yellow fever or other exotic viral diseases. Unlike dengue, a safe and effective vaccine is available for yellow fever although to be effective, vaccination should be used for prevention, not in response to active surveillance 55. Unfortunately, there is unlikely to be sufficient doses of yellow fever vaccine available

\section{Resumo}

A dengue emergiu como problema de saúde pública no Sudeste Asiático durante e após a Segunda Guerra Mundial, e vem se agravando cada vez mais, com epidemias cíclicas progressivamente mais longas e freqüentes de dengue e de febre hemorrágica da dengue. Apesar dessa tendência, a vigilância dessa virose transmitida por vetores permanece basicamente passiva na maioria dos países do Sudeste Asiático, sem apoio laboratorial adequado. O artigo apresenta uma revisão dos fatores que podem ter contribuído para a mudança no perfil epidemiológico da dengue na região, além de discutir os desafios para a prevenção da doença. Analisa-se também uma abordagem regional para a vigilância ativa dos vírus da dengue, focando as áreas urbanas onde eles se mantêm, o que pode representar uma solução à limitação de recursos financeiros, uma vez que a maioria dos países da região tem economias em desenvolvimento. Uma abordagem regional também resultaria em maior probabilidade de sucesso na prevenção da doença, já que a grande circulação de viajantes na região é um fator importante na disseminação dos vírus da dengue.

Dengue; Prevenção de Doenças; Doenças Transmissíveis for Southeast Asia. Thus public health investment in Ae. aegypti control would not only serve as effective preventive measure for epidemic dengue but also yellow fever and other diseases such as chikungunya in Asia.

\section{Conclusion}

The rising trend of dengue fever/dengue hemorrhagic fever incidence with frequent epidemics will likely continue well into the 21 st Century, resulting in significant economic and health impacts $56,57,58$. The necessary infrastructure to reverse this trend is not in place in most dengueendemic countries. This is despite the availability of tools to prevent such epidemics by controlling the principal vector, Ae. aegypti, as well as previous experiences from Cuba and Singapore, where dengue was successfully controlled, although the effects were not sustainable in the long term given the large movement of people and trade material in the dengue-endemic region. To effectively prevent epidemic dengue fever/dengue hemorrhagic fever in the $21^{\text {st }}$ Century will require integrated regional approaches that include effective surveillance, emergency response, mosquito control, case management, and the effective use of both vaccines and antiviral drugs when they become available.

\section{Contributors}

E.-E. Ooi and D. J. Gubler jointly drafted and approved this review. 


\section{References}

1. Gubler DJ. Dengue and dengue hemorrhagic fever. Clin Microbiol Rev 1998; 11:480-96.

2. Gubler DJ. Current research on dengue. In: Harris KF, editor. Current topics in vector research. New York: Springer Verlag; 1987. p. 37-56.

3. Halstead SB. Pathogenesis of dengue: challenges to molecular biology. Science 1988; 239:476-81.

4. Halstead SB, Nimmannitya S, Cohen SN. Observations related to pathogenesis of dengue hemorrhagic fever. IV. Relation of disease severity to antibody response and virus recovered. Yale J Biol Med 1970; 42:311-28.

5. Nimmannitya S. Dengue hemorrhagic fever: diagnosis and management. In: Gubler DJ, Kuno G, editors. Dengue and dengue hemorrhagic fever. Oxford: CAB International; 1997. p. 133-45.

6. Gubler DJ. Dengue and dengue hemorrhagic fever: its history and resurgence as a global public health problem. In: Gubler DJ, Kuno G, editors. Dengue and dengue hemorrhagic fever. Oxford: CAB International; 1997. p. 1-22.

7. Hammon WMcD. Dengue hemorrhagic fever - do we know its cause? Am J Trop Med Hyg 1973; 22:82-91

8. Halstead SB. Dengue hemorrhagic fever. A public health problem and a field for research. Bull World Health Organ 1980; 58:1-21.

9. World Health Organization. Technical guides for diagnosis, treatment, surveillance, prevention and control of dengue hemorrhagic fever. Geneva: World Health Organization; 1975.

10. Gubler DJ, Kuno G, Waterman SH. Neurologic disorders associated with dengue infection. In: Proceedings of the International Conference on Dengue/Dengue Hemorrhagic Fever. Kuala Lumpur: University of Malaysia Press; 1983. p. 290-306.

11. Seet RC, Ooi E-E, Wong HB, Paton NI. An outbreak of primary dengue infection among migrant Chinese workers in Singapore characterized by prominent gastrointestinal symptoms and a high proportion of symptomatic cases. J Clin Virol 2005; 33:336-40.

12. Wilcox BA, Gubler D, Pizer HF. Urbanization and the social ecology of emerging infectious diseases. In: Mayer KH, Pizer HF, editors. Social ecology of infectious diseases. Boston: Elsevier/Academic Press; 2007. p. 113-37.

13. Cummings DA, Irizarry RA, Huang NE, Endy TP, Nisalak A, Ungchusak K, et al. Travelling waves in the occurrence of dengue haemorrhagic fever in Thailand. Nature 2004; 427:344-7.

14. Gubler DJ, Suharyono W, Sumarmo, Wulur H, Jahja E, Sulianto Saroso J. Virological surveillance for dengue haemorrhagic fever in Indonesia using the mosquito inoculation technique. Bull World Health Organ 1979; 57:931-6.

15. Gubler DJ. Cities spawn epidemic dengue virus. Nat Med 2004; 10:129-30.

16. Kay B, Nam VS. New strategy against Aedes aegypti in Vietnam. Lancet 2005; 365:613-7.

17. Nam VS, Nguyen TY, Tran VP, Truong UN, Le QM, Le VL, et al. Elimination of dengue by community programs using Mesocyclops (Copepoda) against Aedes aegypti in Central Vietnam. Am J Trop Med Hyg 2005; 72:67-73.
18. Kroeger A, Lenhart A, Ochoa M, Villegas E, Levy $\mathrm{M}$, Alexander $\mathrm{N}$, et al. Effective control of dengue vectors with curtains and water container covers treated with insecticide in Mexico and Venezuela: cluster randomised trials. BMJ 2006; 332:1247-52.

19. Chang, MS, Setha T, Chanta N, Socheat D, Guillet P, Nathan M. Inhibition of adult emergence of Aedes aegypti in simulated domestic waterstorage containers by using a controlled-release formulation of pyriproxyfen. J Am Mosq Control Assoc 2006; 22:152-4.

20. Gubler DJ, Casta-Valez A. A program for prevention and control of epidemic dengue and dengue hemorrhagic fever in Puerto Rico and the U.S. Virgin Islands. Bull Pan Am Health Organ 1991; 25:237-47.

21. Rigau-Perez JG, Gubler DJ. Surveillance for dengue and dengue hemorrhagic fever. In: Gubler DJ, Kuno G, editors. Dengue and dengue hemorrhagic fever. Oxford: CAB International; 1997. p. 405-24.

22. Gubler DJ. Epidemic dengue/dengue hemorrhagic fever as a public health, social and economic problem in the $21^{\text {st }}$ century. Trends Microbiol 2002; 10:100-3.

23. Ooi E-E, Gubler DJ, Nam VS. Dengue research needs related to surveillance and emergency response. In: Report of the Scientific Working Group Meeting on Dengue. Geneva: World Health Organization; 2007. p. 124-33.

24. Gubler DJ. How effectively is epidemiological surveillance used for dengue programme planning and epidemic response? Dengue Bull 2002; 26: 96-106.

25. Gubler DJ. Aedes aegypti and Aedes aegypti-borne disease control in the 1990s; top down or bottom up. Am J Trop Med Hyg 1989; 40:571-8.

26. George R, Lum LC. Clinical spectrum of dengue infection. In: Gubler DJ, Kuno G, editors. Dengue and dengue hemorrhagic fever. Oxford: CAB International; 1997. p. 89-114.

27. Halstead SB. Epidemiology of dengue and dengue hemorrhagic fever. In: Gubler DJ, Kuno G, editors. Dengue and dengue hemorrhagic fever. Oxford: CAB International; 1997. p. 23-44.

28. Phuong PL, Vries PJ, Nga TT, Giao PT, Hung le Q, Binh TQ, et al. Dengue as a cause of acute undifferentiated fever in Vietnam. BMC Infect Dis 2006; 6:123.

29. Harris E, Videa E, Perez L, Sandoval E, Tellez Y, Perez ML, et al. Clinical, epidemiologic and virologic features of dengue in the 1998 epidemic in Nicaragua. Am J Trop Med Hyg 2000; 63:5-11.

30. Rico-Hesse R, Harrison LM, Salas RA, Tovar D, Nisalak A, Ramos C, et al. Origins of dengue type 2 viruses associated with increased pathogenicity in the Americas. Virology 1997; 230:244-51.

31. Wang E, Ni H, Xu R, Barret AD, Watowich SJ, Gubler DJ, et al. Evolutionary relationships of endemic/ epidemic and sylvatic dengue viruses. J Virol 2000; 74:3227-34.

32. Bennett SN, Holmes EC, Chirivella M, Rodriguez DM, Beltran M, Vorndam V, et al. Selection-driven evolution of emergent dengue virus. Mol Biol Evol 2003; 20:1650-8. 
33. Bennett SN, Holmes EC, Chirivella M, Rodriguez DM, Beltran M, Vorndam V, et al. Molecular evolution of dengue 2 virus in Puerto Rico: positive selection in the viral envelope accompanies clade reintroduction. J Gen Virol 2006; 87:885-93.

34. Deen JL, Harris E, Wills B, Balmaseda A, Hammond $\mathrm{SN}$, Rocha C, et al. The WHO dengue classification and case definitions: time for a reassessment. Lancet 2006; 368:170-3.

35. Sumarmo, Wulur H, Jahja E, Gubler DJ, Suharyono W, Sorensen K. Clinical observations on virologically confirmed fatal dengue infections in Jakarta, Indonesia. Bull World Health Organ 1983; 61: 693-701.

36. Dietz VJ, Gubler DJ, Rigau-Perez JG, Pinheiro F, Schatzmayr HG, Bailey R, et al. Epidemic dengue 1 in Brazil, 1986: evaluation of a clinically based dengue surveillance system. Am J Trop Med Hyg 1990; 131:693-701.

37. Balmaseda A, Hammond SN, Perez MA, Cuadro L, Solano S, Rocha J, et al. Assessment of the World Health Organization scheme for classification of dengue severity in Nicaragua. Am J Trop Med Hyg 2005; 73:1059-62.

38. Hammond SN, Balmaseda A, Perez L, Tellez Y, Saborio SI, Mercado JC, et al. Differences in dengue severity in infants, children and adults in a 3-year hospital-based study in Nicaragua. Am J Trop Med Hyg 2005; 73:1063-70.

39. Ooi E-E, Hart TJ, Tan HC and Chan SH. Dengue seroepidemiology in Singapore. Lancet 2001; 357:685-6.

40. Ooi E-E, Goh KT, Gubler DJ. Dengue prevention and 35 years of vector control in Singapore. Emerg Infect Dis 2006; 12:887-893.

41. Patumanond J, Tawichasri C, Nopparat S. Dengue hemorrhagic fever, Uttaradit, Thailand. Emerg Infect Dis 2003; 9: 1348-50.

42. Corwin AL, Larasati RP, Bangs MJ, Wuryadi S, Arjoso S, Sukri N, et al. Epidemic dengue transmission in southern Sumatra, Indonesia. Trans R Soc Trop Med Hyg 2001; 95:257-65.

43. Pan American Health Organization. Dengue and dengue hemorrhagic fever in the Americas guidelines for prevention and control. Washington DC: Pan Amrican Health Organization; 1994.

44. World Health Organisation. Strengthening implementation of the global strategy for dengue fever/dengue haemorrhagic fever prevention and control. Geneva: World Health Organization; 1999.

45. Chan YC, Chan KL, Ho BC. Aedes aegypti (L.) and Aedes albopictus (Skuse) in Singapore City. 1. Distribution and density. Bull World Health Organ 1971; 44:617-27.

46. Chan KL, Ho BC, Chan YC. Aedes aegypti (L.) and Aedes albopictus (Skuse) in Singapore City. 2. Larval habitats. Bull World Health Organ 1971; 44:629-33.
47. Ho BC, Chan KL, Chan YC. Aedes aegypti (L.) and Aedes albopictus (Skuse) in Singapore City. 3. Population fluctuations. Bull World Health Organ 1971; 44:635-41.

48. Chan KL, Chan YC, Ho BC. Aedes aegypti (L.) and Aedes albopictus (Skuse) in Singapore City. 4. Competition between species. Bull World Health Organ 1971; 44:643-9.

49. Chan YC, Ho BC, Chan KL. Aedes aegypti (L.) and Aedes albopictus (Skuse) in Singapore City. 5. Observations in relation to dengue haemorrhagic fever. Bull World Health Organ 1971; 44:651-8.

50. Chan KL. Singapore's dengue haemorrhagic fever control program: a case study on the successful control of Aedes aegypti and Aedes albopictus using mainly environmental measures as a part of integrated vector control. Tokyo: Southeast Asian Medical Information Center; 1985.

51. Russell BM, McBride WJ, Mullner H, Kay BH. Epidemiological significance of subterranean Aedes aegypti (Diptera: Culicidae) breeding sites to dengue virus infection in Charters Towers, 1993. J Med Entomol 2002; 39:143-5.

52. Montgomery BL, Ritchie SA. Roof gutters: a key container for Aedes aegypti and Ochlerotatus notoscriptus (Diptera: Culicidae) in Australia. Am J Trop Med Hyg 2002; 67:244-6.

53. Reiter P, Gubler DJ. Surveillance and control of urban dengue vectors. In: Gubler DJ, Kuno G, editors. Dengue and dengue hemorrhagic fever. Oxford: CAB International; 1997. p. 425-62.

54. Newton EA, Reiter P. A model of the transmission of dengue fever with an evaluation of the impact of ultra-low volume (ULV) insecticide applications on dengue epidemics. Am J Trop Med Hyg 1992; 47:709-20.

55. Gubler DJ. The changing epidemiology of yellow fever and dengue, 1900 to 2003: a full circle? Comp Immunol Microbiol Infect Dis 2004; 27:319-31.

56. Okanurak K, Sornmami S, Indaratna K. The cost of dengue hemorrhagic fever in Thailand. Southeast Asian J Trop Med Public Health 1997; 28:711-7.

57. Meltzer MI, Rigau-Perez JG, Clark GG, Reiter P, Gubler DJ. Using disability-adjusted life years to assess the economic impact of dengue in Puerto Rico: 1984-1994. Am J Trop Med Hyg 1998; 59: 265-71.

58. Shepard DS, Suaya JA, Halstead SB, Nathan, M, Gubler DJ, Mahoney RT, et al. Cost-effectiveness of a pediatric dengue vaccine. Vaccine 2004; 22:1275-80.

Submitted on 5/Nov/2007 Approved on 25/Feb/2008 